\title{
Effect of seminal prostaglandins on the metabolism of human spermatozoa
}

\author{
R. W. Kelly \\ M.R.C. Unit of Reproductive Biology, 2 Forrest Road, Edinburgh EHI 2QW, U.K.
}

\begin{abstract}
Summary. Study of the effects of 19-hydroxy E prostaglandins on the metabolism of washed ejaculated human spermatozoa showed that these compounds depress the respiration of the spermatozoa, but do not affect the production of lactate. This effect is not seen with the prostaglandins of the $\mathrm{E}$ and $\mathrm{F}$ series.
\end{abstract}

\section{Introduction}

The pharmacological activity of human semen was first demonstrated during attempts at intrauterine insemination (Kurzrok \& Lieb, 1930). Goldblatt (1933) and von Euler (1936) reported effects of seminal extracts on isolated rat myometrial strips and von Euler named the active principle "prostaglandin" (PG). Later the E prostaglandins (PGEs) were isolated from human semen (Samuelsson, 1963) and the more abundant 19-hydroxy E prostaglandins (19-OH PGEs) were subsequently identified (Taylor \& Kelly, 1974; Jonsson, Middleditch \& Desiderio, 1975). The concentrations of PGEs and 19-OH PGEs in the semen of fertile men are $20-180 \mu \mathrm{g} / \mathrm{ml}$ and $80-300 \mu \mathrm{g} / \mathrm{ml}$ respectively (Cooper \& Kelly, 1975). The 19-OH PGEs appear to occur only in primates (Kelly et al., 1976).

Since the first discovery of PGs in semen, most research has been devoted to study of their effects on the smooth muscle of the female reproductive tract. In vitro, PGEs (Bygdeman, Hamberg \& Samuelsson, 1966) and 19-OH PGEs (J. A. Russell, P. L. Taylor, N. E. Skaakebaek \& R. W. Kelly, unpublished observations) relax muscle strips from the uteri of non-pregnant women, whereas in vivo PGEs stimulate the human uterus (Eliasson \& Posse, 1960): PGEs can also relax or contract different segments of the Fallopian tubes in vitro (Sandberg, Ingleman-Sundberg \& Ryden, 1963, 1964) and relax them in vivo (Coutinho \& Maia, 1971; Coutinho, 1971). Martin \& Bygdeman (1975) have shown, by instilling PGE-2 directly into the uterus, that the contractile response of this organ is greatly reduced around the time of ovulation.

In contrast to the large amount of work on the pharmacological action of PGs on the uterus, there is no information on the physiological role of seminal prostaglandins. Whilst it has been generally assumed that they aid sperm transport, this has never been demonstrated. Indeed, relatively little seminal PG may ever reach the uterus, because it is unlikely to pass through the cervix (Moghissi, 1973) or reach the uterus by way of the peripheral circulation because it will be metabolized during passage through the lungs (Samuelsson, Granstrom, Green \& Hamberg, 1971; Hamberg \& Samuelsson, 1971).

The present study was of the effects of seminal PGs on the metabolism of spermatozoa.

\section{Materials and Methods}

\section{Extracts containing prostaglandins}

Human semen $(40 \mathrm{ml})$ was collected in $250 \mathrm{ml}$ ethanol and centrifuged. The supernatant was evaporated to about $1 \mathrm{ml}$ and diluted with $20 \mathrm{ml}$ water. This aqueous solution was acidified with $\mathrm{HCl}$ to $\mathrm{pH} 4$ and extracted with $100 \mathrm{ml}$ ether followed by $150 \mathrm{ml}$ ethyl acetate. The ethyl acetate extract was chromatographed on a Sephadex LH-20 column $(0.3 \times 30 \mathrm{~cm})$ and eluted with ethyl acetate/chloroform/acetic acid (50:50:1 by vol.). Fractions of $2 \mathrm{ml}$ were collected and most of the 19-OH PGEs appeared in fractions 5-7. These fractions, which were free of PGEs, were combined and the PG concentration measured by gas chromatography (Cooper \& Kelly, 1975). 


\section{Suspensions of human spermatozoa}

Semen samples were obtained by masturbation; all the specimens showed normal motility, sperm density and 19-OH PGE concentration. The semen from several men was pooled and diluted with an equal volume of suspension medium (see below) and centrifuged at $1700 \mathrm{~g}$ for $10 \mathrm{~min}$. The sedimented spermatozoa were resuspended in suspension medium by repeated gentle aspiration into a $1 \mathrm{ml}$ glass syringe. The spermatozoa were again centrifuged and resuspended in 1-2 ml suspension medium to give a concentration of approximately $2 \times 10^{8} / \mathrm{ml}$ and a motility of $>30 \%$. Then $0 \cdot 1-1 \mathrm{mg}$ fructose or glucose and $1-5 \mu \mathrm{Ci}\left[\mathrm{U}-{ }^{14} \mathrm{C}\right]$ fructose (sp.act. $296 \mathrm{mCi} / \mathrm{mmol}$ : Radiochemical Centre, Amersham) or [6- ${ }^{14} \mathrm{C}$ ]glucose (sp.act. $59.6 \mathrm{mCi} / \mathrm{mmol}$ : Radiochemical Centre, Amersham) were added. The PGs (see Table 1) in solution were evaporated at the bottom of $4 \mathrm{ml}$ culture tubes, the suspension of spermatozoa $(0 \cdot 1 \mathrm{ml})$ was added and the tubes were sealed with a rubber cap. After incubating for $90 \mathrm{~min}$ at $37^{\circ} \mathrm{C}, 30 \mu \mathrm{l} 6 \mathrm{~N}-\mathrm{HCl}$ were added through the seal and the tubes were shaken for $5 \mathrm{~min}$. Some tubes were incubated with shaking at 105 strokes/min but experiment showed that shaking was not necessary for the maximum production of $\mathrm{CO}_{2}$ because of the very small oxygen uptake. A $10 \mathrm{ml}$ disposable syringe containing a pellet of $\mathrm{KOH}$ was used to withdraw a gas sample from an incubation tube by inserting the needle through the seal and pulling the plunger to the $5 \mathrm{ml}$ mark then withdrawing the needle under water. The water entered the syringe, and the needle was removed. The syringe was then capped and shaken to dissolve the pellet of $\mathrm{KOH}$ and the $\mathrm{CO}_{2}$ in the resulting solution. The volume of gas withdrawn could be measured at atmospheric pressure by the graduations of the syringe and was consistently $2 \cdot 3 \mathrm{ml}$. The volume of $\mathrm{CO}_{2}$ absorbed was negligible compared with the volume of gas sampled. Recovery experiments with sodium $\left[{ }^{14} \mathrm{C}\right]$ carbonate showed that the mean recovery of labelled $\mathrm{CO}_{2}$ was $93 \pm 6 \%$ S.D. $(n=10)$. Aliquots $(1 \mathrm{ml})$ of the alkali solution were mixed with PPO/POPOP scintillant in toluene with Triton X-100 as the emulsifying agent. After equilibration for $12 \mathrm{~h}$ at $4^{\circ} \mathrm{C}$ the samples were counted in a Packard Tricarb scintillation counter with an efficiency of $65 \%$.

Control incubations with sperm-free buffer or with spermatozoa heated to $100^{\circ} \mathrm{C}$ gave $<150$ counts labelled $\mathrm{CO}_{2} / 10^{8}$ spermatozoa.

\section{Suspension media}

Phosphate buffer. This contained $0.02 \mathrm{M}-\mathrm{Na}_{2} \mathrm{HPO}_{4}$ and $0.15 \mathrm{~N}-\mathrm{NaCl}$ which was brought to $\mathrm{pH}$ $7 \cdot 4$ with $\mathrm{KH}_{2} \mathrm{PO}_{4}$.

Phosphate-carbonate buffer. This contained 0.02 $\mathrm{M}-\mathrm{Na}_{2} \mathrm{HPO}_{4}, 0 \cdot 15 \mathrm{M}-\mathrm{NaCl}$ and $0.04 \mathrm{M}-\mathrm{NaHCO}$.

Low-phosphate tris buffer. This contained 0.02 M-2-amino-(hydroxymethylpropane-1,3-diol), $0.11 \mathrm{~m}-\mathrm{NaCl}, 0.006 \mathrm{M}-\mathrm{NaHCO}_{3}, 0.004 \mathrm{M}-\mathrm{KCl}, 0.002 \mathrm{M}-\mathrm{MgSO}_{4}, 0.0002 \mathrm{M}-\mathrm{CaCl}_{2}, 0.003 \mathrm{M}-\mathrm{KH}_{2} \mathrm{PO}_{4}$, $0.05 \mathrm{~g}$ human serum albumin (Sigma Chemical Co., London)/litre, 83,000 units penicillin-G (Sigma, London)/litre and $\mathbf{0 . 1} \mathrm{g}$ streptomycin sulphate (Sigma, London)/litre. The medium was brought to pH 7.4 with $1 \mathrm{~N}-\mathrm{HCl}$.

\section{Measurements of metabolites}

Labelled acidic metabolites were measured for samples fromevery series of incubations by chromatography of the acidified incubation mixture on $0.5 \times 4 \mathrm{~cm}$ columns of Amberlite (B.D.H., Poole) IRA 47 resin and elution with $2 \times 20 \mathrm{ml} 1 \%$ fructose followed by $2 \times 20 \mathrm{ml} 1 \mathrm{~N}-\mathrm{KOH}$. Aliquots $(1 \mathrm{ml})$ of each fraction were counted. The precision of this method of estimating lactate was determined by replicate analysis of a labelled lactate/fructose mixture. The labelled material of the acidic fraction from the incubation was identified as lactic acid by thin-layer chromatography. The recovery of lactate was $94 \%$ and the precision over 7 assays was $3.4 \%$ (S.D.)

\section{Assessment of motility}

Motility was assessed as the number of motile spermatozoa with forward progression. Degrees of forward progression were not distinguished. Motility was assessed after the start of an incubation by including separate tubes for the purpose.

The significance of differences was determined with Student's $t$ test. 


\section{Results}

Synthetic 19-OH PGE-1 (and to a lesser extent 19-OH PGE-2) and the 19-OH PGE fraction of human semen decreased the amount of labelled $\mathrm{CO}_{2}$ produced from fructose by washed spermatozoa (Table 1). The effect of the 19-OH PGEs was always significant, although the radioactivity liberated as $\mathrm{CO}_{2}$, even in the control sample, was a small percentage $(<1 \%)$ of that added. This low $\mathrm{CO}_{2}$ production is consistent with the low $\mathrm{ZO}_{2}$ reported for human semen (Peterson \& Freund, 1970a).

Table 1. The effect of various prostaglandins (PGs) on $\mathrm{CO}_{2}$ production by washed human spermatozoa (mean \pm S.D., no. of incubations in parentheses)

\begin{tabular}{|c|c|c|c|c|c|c|}
\hline \multirow[b]{2}{*}{ PG* } & \multirow[b]{2}{*}{$(\mu \mathrm{g} / \mathrm{ml})$} & \multicolumn{2}{|c|}{${ }^{14} \mathrm{CO}_{2}$ counts $/ 10^{8}$ spermatozoa } & \multirow[b]{2}{*}{$\%$ Change } & \multirow[b]{2}{*}{$\boldsymbol{P}$} & \multirow[b]{2}{*}{$\begin{array}{l}\text { Procedural } \\
\text { differences }\end{array}$} \\
\hline & & $\begin{array}{c}\text { Control } \\
\text { incubations }\end{array}$ & Test incubations & & & \\
\hline $\begin{array}{l}\text { 19-OH E-1 + 19-OH E-2 } \\
\text { (semen extract) }\end{array}$ & $52+52$ & $2065 \pm 337(4)$ & $845 \pm 119(4)$ & -59 & $<0.001$ & \\
\hline $\begin{array}{l}\text { 19-OH E-1 + 19-OH E-2 } \\
\text { (synthetic) }\end{array}$ & $150+150$ & $798 \pm 84(4)$ & $539 \pm 62(4)$ & -32 & $<0.01)$ & Same sperm \\
\hline $\begin{array}{l}\mathrm{E}-1+\mathrm{E}-2 \\
\mathrm{~F}-1+\mathrm{F}-2 \alpha\end{array}$ & $\left.\begin{array}{l}150+150 \\
150+150\end{array}\right\}$ & & $\begin{array}{l}836 \pm 92(4) \\
780 \pm 32(4)\end{array}$ & $\begin{array}{l}+5 \\
-2\end{array}$ & $\begin{array}{l}\text { N.S. } \\
\text { N.S. }\end{array}$ & preparation \\
\hline $\begin{array}{l}\text { 19-OH E-1 + 19-OH E-2 } \\
\text { (synthetic) }\end{array}$ & $200+200$ & $6311 \pm 905(7)$ & $3287 \pm 521(4)$ & -48 & $<0.001$ & \\
\hline $\begin{array}{l}\text { 19-OH E-1 } \\
\text { (synthetic) }\end{array}$ & 400 & & $2504 \pm 39(4)$ & -60 & $<0.001$ & $\begin{array}{l}\text { Same sperm } \\
\text { preparation }\end{array}$ \\
\hline $\begin{array}{l}\text { 19-OH E-2 } \\
\text { (synthetic) }\end{array}$ & 400 & & $5361 \pm 370(4)$ & -15 & $<0.01$ & \\
\hline
\end{tabular}

* The synthetic $19-\mathrm{OH}$ prostaglandins were mixtures of epimers at 19 , and were racemic.

\section{Effect of suspension media}

Phosphate buffer. The results obtained using this buffer are shown in Table 1.

Low-phosphate tris buffer. In an incubation with this buffer there was a $36 \%$ depression in labelled $\mathrm{CO}_{2}$ production: the control sample gave $32,310 \pm 2830$ (S.D.) counts $/ 10^{8}$ spermatozoa $(n=7)$, whereas the sample containing $150 \mu \mathrm{g}$ synthetic $19-\mathrm{OH}$ PGE-1/ml gave $20,700 \pm 2100$ counts $/ 10^{8}$ spermatozoa $(n=4 ; P<0.001)$.

Phosphate-carbonate buffer. Experiments with this buffer gave $33 \%$ depression in ${ }^{14} \mathrm{CO}_{2}$ production, from $6640 \pm 584$ (S.D.) for control incubations to $4412 \pm 314$ counts $/ 10^{8}$ spermatozoa for incubations containing $52 \mu \mathrm{g} 19-\mathrm{OH}$ PGE-1 + $52 \mu \mathrm{g}$ 19-OH PGE-2 $(n=6 ; P<0.001)$. A further experiment using this buffer with $5 \mu \mathrm{Ci}\left[6-{ }^{14} \mathrm{C}\right]$ glucose $+1 \mathrm{mg}$ glucose as substrate gave a depression from control incubations of $2962 \pm 506$ counts $/ 10^{8}$ spermatozoa to $996 \pm 132$ counts when $250 \mu \mathrm{g}$

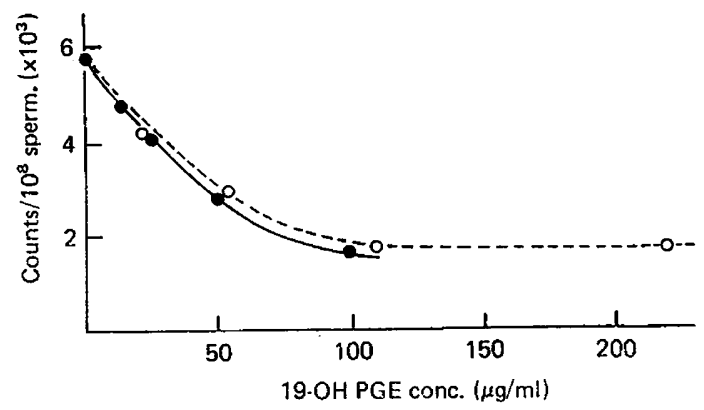

Text-fig. 1. The production of ${ }^{14} \mathrm{CO}_{2}$ from washed ejaculated human spermatozoa incubated with different concentrations of natural $(O)$ or synthetic $(\bullet)$ 19-hydroxy E prostaglandins. The latter values are represented as divided by 4 to account for the racemic nature of the product. 
19-OH PGE-1 (synthetic) and $225 \mu \mathrm{g}$ PGE-1 were added ( $n=5 ; P<0.001)$. In this last experiment the lactate production was significantly $(P<0.02)$ lower in the control samples $(42.8 \pm 2.9 \%$ of radioactivity) compared with that in the PG-containing sample (46.6 $\pm 1.3 \%$ radioactivity).

As shown in Text-fig. 1, there was close similarity of the effects of natural and synthetic 19-OH PGEs, especially when the results with the synthetic compound were divided by 4 to allow for the presence of the three racemic and epimeric forms which are probably inactive. The maximum effect of the natural PGs occurred at a concentration of $90 \mu \mathrm{g} / \mathrm{ml}$, which is near the lower end of the normal range of 19-OH PGE levels in human semen (Cooper \& Kelly, 1975).

No significant differences were observed between the lactate production of suspensions with and without PGs except when PGE-1 was included with 19-OH PGE-1 and $\left[6-{ }^{14} \mathrm{C}\right]$ glucose was the substrate; in these incubations the lactate production increased significantly. Observations of motilities after incubation showed no differences between control spermatozoa and those to which PGs had been added.

\section{Discussion}

Studies of the metabolism of ejaculated spermatozoa in human semen are difficult because of their relatively low respiration. However, satisfactory results have been obtained using isotopically labelled substrates (Terner, 1960; Peterson \& Freund, 1968; Eliasson, Murdoch \& White, 1968), although Eliasson et al. (1968) found no effect of PGE-1 on human spermatozoa. These techniques were used in the present study to examine for the first time the effect of 19-OH PGEs, compounds only recently identified in human semen (Taylor \& Kelly, 1974; Jonsson, Middleditch \& Desiderio, 1975).

All the results show that 19-OH PGEs have a marked inhibitory action on sperm respiration. This effect is not seen with PGs of the E or F series (Table 1). A similar effect on the inhibition of respiration was seen when $\left[{ }^{14} \mathrm{C}\right]$ glucose labelled at the 6 position was used as the substrate, indicating that the effect is not primarily on the pyruvate dismutase pathway, which might exist in human spermatozoa (Terner, 1960; Peterson \& Freund, 1968), because carbon 6 of glucose does not appear in the $\mathrm{CO}_{2}$ released by that route.

Although the effects of 19-OH PGEs on labelled $\mathrm{CO}_{2}$ production were highly significant, respiration in ejaculated human spermatozoa is a minor metabolic pathway and therefore it is not surprising that the effects of 19-OH PGEs on respiration were not reflected in changes of motility or lactate production. However, it is possible that such effects could be seen if more precise methods were available for measuring these two parameters. A much greater inhibitory effect on respiration and therefore a measurable effect on motility might be expected if these experiments were repeated with epididymal spermatozoa, because ejaculated spermatozoa, having already been exposed to PGs in the semen, may be partly refractory towards added PGs.

Previous workers have shown that the suspension medium can have an effect on the respiratory process of spermatozoa (Mann, 1964, p. 346). Most of the experiments in this study used phosphatebuffered saline as the suspension medium, but other media were used to demonstrate the independence of the effect from the medium. One suspension medium with a higher buffering capacity was phosphate-carbonate-buffered saline and results similar to those from experiments with the phosphate buffer were obtained. Another suspension medium used in this study had a very low phosphate concentration $(0.003 \mathrm{M})$ compared with the much higher concentrations (around $0.1 \mathrm{M}$ ) which cause inhibition of respiration. Since this medium also contained calcium and magnesium ions, the results, which showed a highly significant depression of labelled $\mathrm{CO}_{2}$ released from the suspensions of spermatozoa with added PGs, demonstrate that the effects of PGs were not restricted to calcium- or magnesium-deficient systems.

Although human spermatozoa possess the cytochrome system necessary for aerobic metabolism (Mann, 1951), the absence of an appreciable Pasteur effect (Peterson \& Freund, 1974) has led to debate of whether human spermatozoa respire aerobically in seminal plasma or rely entirely on anaerobic fructolysis for energy. It is now generally accepted that human spermatozoa do respire, but that the oxygen uptake is low (Peterson \& Freund, 1968). The fact that physiological concentrations 
of 19-OH PGEs reduce sperm respiration may explain their low respiratory activity in seminal plasma. Previous work has shown that $\mathrm{ZO}_{2}$ values are 2-3 times higher for spermatozoa suspended in buffered salt solutions compared with those of spermatozoa suspended in seminal plasma (Peterson \& Freund, 1970a; Eliasson, 1971) and Eliasson (1971) has proposed that human seminal plasma normally contains a factor that depresses sperm respiration. The results reported here suggest that this factor is 19-OH PGE.

Human seminal plasma is a rich source of fructose (Mann, 1946) and ejaculated spermatozoa do not therefore need to depend on aerobic metabolism as do epididymal spermatozoa. The fructose supply in semen may be of the greatest value when oxygen is scarce, e.g. in semen of high density immediately after ejaculation (Mann, 1964, p. 293). In such an environment, where the oxygen supply might be gradually exhausted and at a time when vigorous motility is essential, continued aerobic metabolism might result in competition for the ions or cofactors which control glycolysis. It is known that the control of glycolysis in human spermatozoa is not regulated by the amount of glycolytic enzymes or substrates but rather by the concentration of an unidentified ion or cofactor (Peterson \& Freund, 1970b). Exactly where the spermatozoa change from aerobic to anaerobic metabolism is not known; if $60-70 \%$ of spermatozoa are ejaculated from the region of the epididymis (Freund \& Davis, 1969) then the change must occur during ejaculation. But for the spermatozoa which are stored in the ampulla of the vas deferens, where fructose and PGs might be accessible, the change may occur when the ampulla is reached. When ejaculated spermatozoa ascend the female reproductive tract they gradually escape from an environment of seminal PGs, and may revert to aerobic metabolism during their ascent. In the rhesus monkey the oxygen tension in the oviduct around mid-cycle is sufficient to maintain aerobic metabolism of spermatozoa (Maas, Storey \& Mastroianni, 1976).

Pento, Cenendella \& Inskeep (1970) have shown that PGEs inhibit the aerobic metabolism of sheep epididymal spermatozoa, although no effect could be seen on washed ejaculated spermatozoa. Such an action of PGEs could be expected as they are known to affect carbohydrate metabolism in other tissues. In the dog heart PGE-1 inhibits lipolysis, increases glucose uptake and decreases myocardial oxygen consumption (Glaviano \& Masters, 1971). In the ovary PGE increases the accumulation of lactate (Ahren et al., 1973; Lieberman, Ahren, Tsafriri, Bauminger \& Lindner, 1975), and a similar effect is seen in the myometrium of the pregnant rhesus monkey (Beatty \& Bocek, 1972).

The above evidence implicates the 19-OH PGEs as moderators of carbohydrate metabolism in spermatozoa and their action on human myometrial strips may be due to a similar moderation of carbohydrate metabolism. Which of these is the primary function of seminal prostaglandins cannot at present be decided.

I thank Professor R. V. Short for help and encouragement in this study; Professor T. Mann and Professor H. R. Lindner for help in preparing the manuscript; Dr N. S. Crossley, I.C.I. (Pharmaceuticals) Ltd, for the 19-hydroxy prostaglandins; and Dr J. E. Pike, Upjohn Co., for the prostaglandins E-1, E-2, F-1 $\alpha$ and F-2 $\alpha$.

\section{References}

Ahren, K., Hamberger, L., Herlitz, H., Hillensjo, T., Nillson, L., Perklev, T. \& Selstam, G. (1973) Aspects of the mechanisms of action of gonadotrophins. In The Endocrine Function of the Human Testis, pp. 251-265. Eds V. H. T. James, M. Serio \& L. Martini. Academic Press, New York.

BeatTy, C.H. \& BoceK, R.M. (1972) Prostaglandins: their effects on the carbohydrate metabolism of myometrium from rhesus monkeys. Endocrinology 90, 1295-1300.
Bygdeman, M., Hamberg, M. \& Samuelsson, B. (1966) The content of different prostaglandins in human seminal fluid and their threshold doses on the human myometrium. Mem. Soc. Endocr. 14, 49-64.

Cooper, I. \& Kelly, R.W. (1975) The measurement of $E$ and 19-hydroxy $E$ prostaglandins in human seminal plasma. Prostaglandins 10, 507-514.

Coutinho, E.M. (1971) Tubal and uterine motility. In Nobel Symposium 15, Control of Human Fertility, pp. 97-115. Eds E. Diczfalusy \& U. Borell. Stockholm. Alquist \& Wiksell. 
Couninho, E.M. \& MAIA, H.S. (1971) The contractile response of the human uterus, Fallopian tubes, and ovary to prostaglandins in vivo. Fert. Steril. 22, 539 . 543.

Eliasson, R. (1971) Oxygen consumption of human spermatozoa in seminal plasma and a Ringer solution. J. Reprod. Fert. 27, 385-389.

Eliasson, R. \& Posse, N. (1960) The effect of prostaglandin on the non pregnant human uterus in vivo. Acta obstet. gynec. scand. 39, 112-126.

Eliasson, R. Murdoch, R.N. \& White, I.G. (1968) The metabolism of human spermatozoa in the presence of prostaglandin $\mathrm{E}_{1}$. Acta physiol. scand. 73, 379-382.

FreUND, M. \& DAVIs, J.E. (1969) Disappearance rate of spermatozoa from the ejaculate following vasectomy. Fert. Steril. 20, 163-170.

Glaviano, V.V. \& Masters, T. (1971) Inhibitory action of intracoronary prostaglandin $E_{1}$ on myocardial lipolysis. Am. J. Physiol 220, 11871193.

GoldblatT, M.W. (1933) A depressor substance in seminal fluid. Chem. \& Ind. 52, 1056-1057.

Hamberg, M. \& Samuelsson, B. (1971) On the metabolism of prostaglandins $E_{1}$ and $E_{2}$ in man. J. biol. Chem. 246, 6713-6721.

Jonsson, H.T., Middleditch, B.S. \& Desiderio, D.M. (1975) Prostaglandins in human seminal fluid: two novel compounds. Science, N.Y. 187, 1093-1094.

Kelly, R.W., Taylor, P.L., Hearn, J.P., Short, R.V., MARTIN, D.E. \& MARSTON, J.H. (1976) 19-Hydroxyprostaglandin $E_{1}$ as a major component of the semen of primates. Nature, Lond. 260, 544-545.

KuRzRoK, R. \& LieB, C. (1930) Biochemical studies of human semen. II. Action of semen on the human uterus. Proc. Soc. exp. Biol. Med. 28, 268-272.

Lieberman, M.E., AHren, K., Tsafriri, A., BaUminger, S. \& LINDNER, H.R. (1975) Relationship between glycolysis and steroidogenesis in cultured graafian follicles stimulated by $\mathrm{LH}$ or prostaglandin $\mathrm{E}_{2} . J$. Steroid Biochem. 6, 1445-1449.

MaAs, D.H.A., Storey, B.T. \& MastroianNi, L. (1976) Oxygen tension in the oviduct of the Rhesus monkey (Macaca mulatta). Fert. Steril. 27, 13121317.

MANN, T. (1946) Studies on the metabolism of semen. Fructose as a normal constituent of seminal plasma. Site of formation and function of fructose in semen. Biochem. J. 40, 481-491.

MANN, T. (1951) Studies on the metabolism of semen. Cytochrome in human spermatozoa. Biochem. J. 48, 386-389.
ManN, T. (1964) The Biochemistry of Semen and of the Male Reproductive Tract. Methuen, London.

Martin, J.N. \& Bygdeman, M. (1975) The effect of locally administered $\mathrm{PGE}_{2}$ on the contractility of the non-pregnant human uterus in vivo. Prostaglandins 10,253-265.

Moghissi, K.S. (1973) Sperm migration through the human cervix. In Cervical Mucus in Human Reproduction, pp. 128-152. Eds M. Elstein, K. S. Moghissi \& R. Borth. Scriptor, Copenhagen.

Pento, J.T., Cenedel, A, R.J. \& Inskeep, E.K. (1970) Effects of prostaglandin $E_{1}$ and $F_{1} a$ upon carbohydrate metabolism of ejaculated and epididymal ram spermatozoa in vitro. J. Anim. Sci. 30, 409-411.

Peterson, R.N. \& Freund, M. (1968) An evaluation of the respiratory capacity of human spermatozoa. $J$. Reprod. Fert. 17, 357-372.

Peterson, R.N. \& Freund, M. (1970a) ATP synthesis and oxidative metabolism in human spermatozoa. Biol. Reprod. 3, 47-54.

Peterson, R.N. \& Freund, M. (1970b) Profile of glycolytic enzyme activities in human spermatozoa. Fert. Steril. 21, 151-158.

Peterson, R.N. \& Freund, M. (1974) Citrate formation from exogenous substrates by washed human spermatozoa. J. Reprod. Fert. 38, 73-79.

SAMUELSSON, B. (1963) Isolation and identification of prostaglandins from human seminal plasma. J. biol. Chem. 238, 3229-3234.

Samuelsson, B., Granstrom, E., Green, K. \& HamBERG, M. (1971) Metabolism of prostaglandins. Ann. N.Y. Acad. Sci. 180, 138-163.

SANDBERG, F., Ingleman-Sundberg, A. \& Ryden, G. (1963) The effect of prostaglandin $E_{1}$ on the human uterus and Fallopian tubes in vitro. Acta obstet. gynec. scand. 42, 269-278.

SANDberG, F., Ingleman-SundberG, A., \& Ryden, G. (1964) The effect of prostaglandin $E_{2}$ and $E_{3}$ on the human uterus and Fallopian tubes in vitro. Acta obstet. gynec. scand. 43, 95-102.

TAYLOR, P.L. \& KELLY, R.W. (1974) 19-Hydroxylated $E$ prostaglandins as the major prostaglandins of human semen. Nature, Lond. 250, 665-667.

Terner, C. (1960) Oxidation of exogenous substrates by isolated human spermatozoa. Am. J. Physiol. 198, 48-50.

VON EULER, U.S. (1936) On the specific vasodilating and plain muscle stimulating substances from accessory genital glands in man and certain animals (prostaglandin and vesiglandin). J. Physiol., Lond. 88, 213234.

Received 8 September 197 